\title{
APLICAÇÃO DE ÍNDICES DE DIAGNÓSTICO DE HIDROCARBONETOS ALIFÁTICOS NA AVALIAÇÃO DE IMPACTO AMBIENTAL EM UM DOS PRINCIPAIS AFLUENTES DA MARGEM DIREITA DO RIO AMAZONAS
}

\author{
L. M. de CASTRO ${ }^{1}$, S. D. da ROCHA ${ }^{1}$, L. M. da $\operatorname{SILVA}^{1}$ e T. C. S. de OLIVEIRA ${ }^{1}$ \\ ${ }^{1}$ Universidade Federal do Amazonas, Departamento de Química \\ E-mail para contato: lore.mady@gmail.com
}

\begin{abstract}
RESUMO - A presença de hidrocarbonetos alifáticos em águas superficiais é atribuída ao aporte de substâncias tanto de origem natural como de fontes antropogênicas. Uma ferramenta auxiliar que permite a aferição entre os fatores de aporte dessas substâncias nos recursos hídricos consiste no uso de índices de diagnóstico dos hidrocarbonetos alifáticos quantificados das amostras. O local de amostragem é um trecho do rio Madeira entre os municípios de Porto Velho-RO, Manicoré e Borba-AM. Os n-alcanos (n- $\mathrm{C}_{12}$ ao n- $\left.\mathrm{C}_{40}\right)$ e os isoprenóides pristano e fitano foram identificados e quantificados, pelo método de padronização interna (padrão interno: $n-C_{24} d$ ) por cromatografia gasosa com detector de ionização de chama (GC-DIC). Entre os pontos analisados, verificou-se através da presença marcante de MCNR e das razões $n-C_{17} /$ pristano e $n-C_{18} /$ fitano que o ambiente sofreu contaminação recente de caráter petrogênico apesar das razões $<\mathrm{nC}_{20} / \mathrm{nC}_{21}>$, pristano/fitano e do n-alcano mais abundante indicarem que o aporte predominante de n-alcanos nesse ambiente é de origem biogênica.
\end{abstract}

\section{INTRODUÇÃO}

O crescimento demográfico expressivo aliado à expansão industrial das grandes metrópoles tem influenciado de forma significativa no aumento da pressão das atividades antrópicas sobre os recursos naturais. Esta realidade tem acarretado em impactos como o comprometimento dos recursos, em alguns casos irreversivelmente, ou na diminuição da oferta destes (Goulart e Callisto, 2003). Os mananciais localizados próximos a zonas urbanas sofrem significativamente com as alterações na superfície terrestre. A exposição dos corpos hídricos a poluição desenfreada resulta na necessidade de conhecer em profundidade o funcionamento dos ecossistemas além dos fatores que atuam sobre eles, no intuito de se obter referenciais que permitam a avaliação da magnitude dos impactos ambientais decorrente das alterações antrópicas (Lougon et al., 2009).

O conhecimento do potencial carcinogênico, mutagênico e tóxico de alguns compostos orgânicos (Aboul-Kassim e Simoneit, 2001) tem resultados em esforços para a verificação da importância destes como indicadores ambientais de poluição dos corpos hídricos. Entre estes compostos destacam-se os hidrocarbonetos alifáticos que são constituídos por uma quantidade vasta de compostos que possuem origem tanto natural (plantas terrestres vasculares, por 
exemplo) ou antropogênica. Dentre as fontes antropogênicas podem ser citadas: derrame de petróleo, combustão parcial do petróleo e seus derivados, queimadas que ocorrem em florestas e a degradação diagenética de precursores biogênicos.

Os hidrocarbonetos alifáticos de origem petrogênica aparecem como uma sequência completa de n-alcanos de cadeia longa e curta, enquanto que os originados a partir de plantas vasculares aparecem como uma um sequência de n-alcanos ímpares $\left(n-C_{23}\right.$ à n- $C_{35}$, onde n$\mathrm{C}_{27}, \mathrm{n}-\mathrm{C}_{29}$ e n-C $\mathrm{C}_{31}$ ) (Readman et al., 2002; Eglinton e Hamilton, 1967). Carreira et. al (2009) afirma que a síntese biogênica acarreta na produção de n-alcanos ímpares, enquanto que os de origem petrogênica resultam na distribuição relativamente uniforme de n-alcanos de cadeias pares e ímpares. A presença de $n$-alcanos leves, como o $n-C_{17}$, principalmente, indica que o aporte da matéria orgânica é de origem planctônica.

Entretanto, quando se trata de monitoramento, a utilização de hidrocarbonetos como indicadores ambientais pode não ser a melhor escolha, devido alguns destes apresentarem frequentemente concentrações abaixo do limite de detecção das metodologias usualmente adotadas (Dickenson et al., 2011). O uso de índices de diagnóstico, apesar de não minimizar o problema anteriormente citado, tem se mostrado uma ferramenta auxiliar efetiva na aferição das fontes de aporte de hidrocarbonetos nos recursos hídricos. Este estudo averiguará para cada ponto de amostragem a concentração total de n-alcanos de $n-C_{12}$ a n- $C_{40}$, a mistura complexa não resolvida (MCNR), a fração total de alifáticos, além das seguintes razões: resolvidos/MCNR, $\leq \mathrm{C}_{20} / \mathrm{C}_{21} \geq$, pristano/fitano, $\mathrm{n}-\mathrm{C}_{17} /$ pristano e $\mathrm{n}-\mathrm{C}_{18} /$ fitano; com o objetivo de verificar quais as fontes predominantes de hidrocarbonetos alifáticos nas águas de um trecho do rio Madeira.

\section{METODOLOGIA}

\section{1. Área de estudo}

A região de estudo (Figura 1) abrange um trecho do rio Madeira localizado entre os estados de Rondônia e Amazonas em pontos localizados as margens dos municípios de Porto Velho, Manicoré e Borba.

Cada ponto amostrado foi devidamente identificado, georreferenciado e listado na Tabela 1 no ato da coleta.

Tabela 1 - Descrição e códigos dos pontos de amostragem e suas respectivas coordenadas geográficas

\begin{tabular}{|c|c|c|c|}
\hline \multirow{2}{*}{ Código da amostra } & \multicolumn{2}{|c|}{ Coordenadas } & \multirow{2}{*}{ Município } \\
\hline & Latitude & Longitude & \\
\hline Rio Madeira VII & $8^{\circ} 41^{\prime} 17.91$ '’ $\mathrm{S}$ & $63^{\circ} 55^{\prime} 7.10^{\prime \prime} \mathrm{O}$ & Porto Velho \\
\hline Rio Madeira IX & $5^{\circ} 47^{\prime} 10.25^{\prime \prime} \mathrm{S}$ & $61^{\circ} 17^{\prime} 28.65^{\prime \prime} \mathrm{O}$ & Manicoré \\
\hline Rio Madeira X & $4^{\circ} 53^{\prime} 34.37^{\prime \prime} \mathrm{S}$ & $60^{\circ} 1 ’ 24.59^{\prime \prime} \mathrm{O}$ & $\begin{array}{c}\text { Borba/Fazenda Vista } \\
\text { Alegre }\end{array}$ \\
\hline
\end{tabular}


Figura 1 - Região da bacia Amazônica abrangida neste estudo

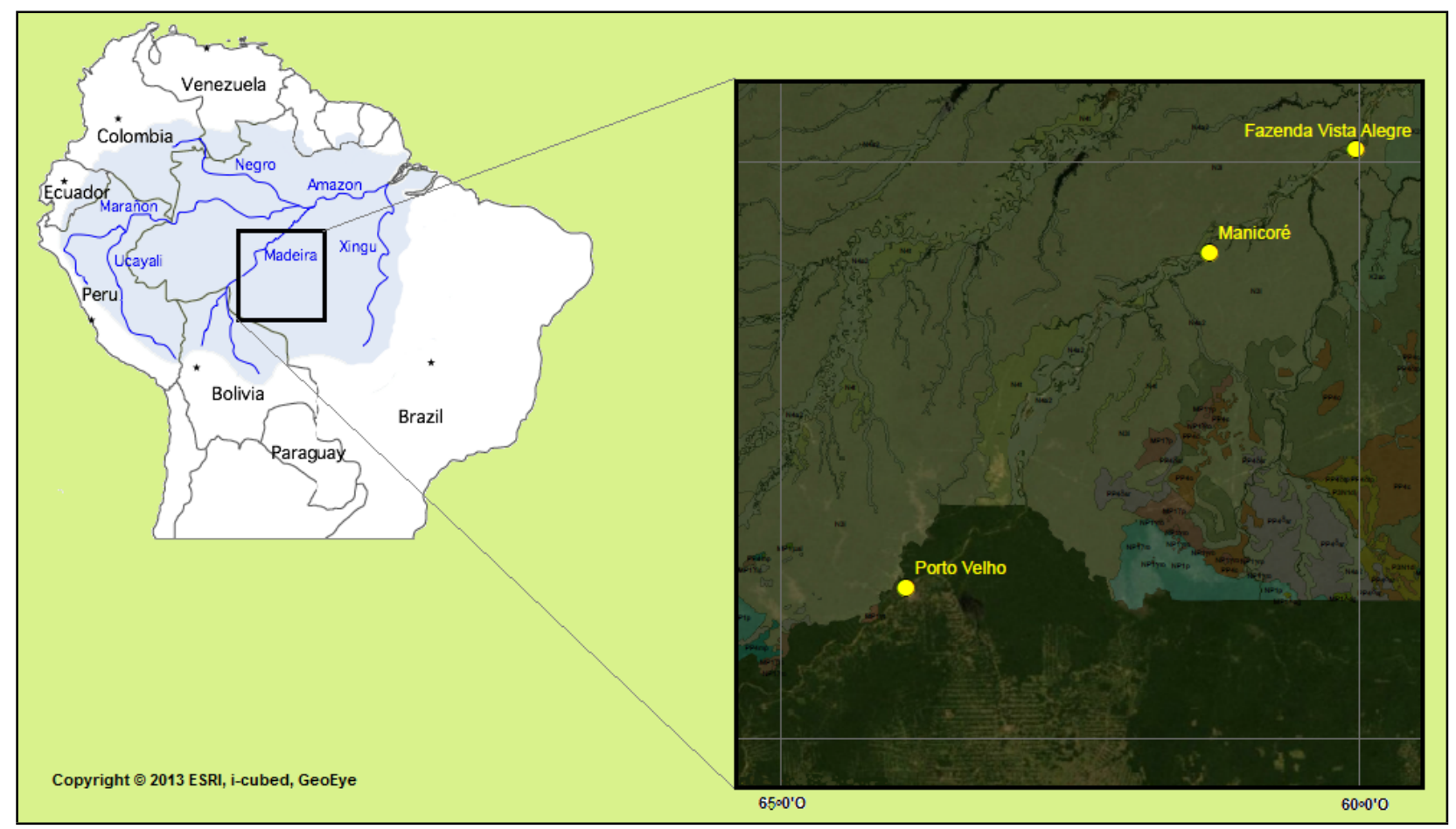

\subsection{Amostragem e procedimentos analíticos}

As amostras de água foram coletadas com o auxílio de garrafa van Dorn submersa à $30 \mathrm{~cm}$ abaixo da lâmina d'água e, em seguida, direcionadas para garrafas de vidro de $1000 \mathrm{~mL}$. As duplicatas das amostras foram misturadas para a realização da extração conforme a metodologia da Agência de Proteção Ambiental dos Estados Unidos - EPA 3510. A extração líquido-líquido ocorreu após adição de 3 porções de $100 \mathrm{~mL}$ de diclorometano seguida de agitação vigorosa para posterior recolhimento da fase orgânica em frasco de vidro. Antes desta etapa, são adicionados na mistura os padrões deuterados: $n-C_{30} D_{62}$ (2500ng) para controle da fração alifática. $\mathrm{O}$ volume do extrato foi reduzido em Turbo Vapp para posterior separação da fração saturada.

Os hidrocarbonetos alifáticos foram extraídos por cromatografia líquida em coluna de sílica/alumina $(10,0 \mathrm{~g}$ de sílica $+7,0 \mathrm{~g}$ de alumina $+1,0 \mathrm{~g}$ de sulfato de sódio). A coluna foi eluída com $60 \mathrm{~mL}$ de hexano, onde o extrato obtido é concentrado em sistema TurboVap ${ }^{\circledR}$, completado para $1 \mathrm{~mL}$ e foram adicionados os padrões internos de quantificação. Estes foram identificados e quantificados pelo método de padronização interna, onde o padrão interno utilizado foi o n- $\mathrm{C}_{24} \mathrm{~d}$ e a concentração da mistura complexa não-resolvida foi obtida com detector de ionização por chama (CG-DIC) segundo a metodologia EPA-8015B. O equipamento utilizado foi um cromatógrafo Thermo Finnigan, modelo Focus GC com detector DIC. A coluna foi do tipo J\&W DB $5(30 \mathrm{~m} \times 0,32 \mathrm{~mm} \times 0,25 \mu \mathrm{m})$. O gás de arraste utilizado foi o hélio à um fluxo de $2 \mathrm{~mL} \cdot \mathrm{min}^{-1}$. Os limites de detecção e quantificação foram de $0,011 \mu \mathrm{g} . \mathrm{L}^{-1}$ e $0,022 \mu \mathrm{g} . \mathrm{L}^{-1}$, respectivamente. 


\section{RESULTADOS E DISCUSSÕES}

Inicialmente, os hidrocarbonetos foram caracterizados em relação ao somatório total de n-alcanos, de hidrocarbonetos resolvidos, da mistura complexa não-resolvida (MCNR) e de alifáticos para cada ponto de coleta. Segundo Carreira et. al (2009), a presença de nalcanos de cadeia longa com número ímpar indica que a possível fonte da matéria orgânica são as ceras epicuticulares oriundas de plantas superiores o que é observado nos pontos Rio Madeira IX e X.

A MCNR é considerada por ser uma mistura de muitos isômeros de estrutura complexa e homólogos de hidrocarbonetos cíclicos e ramificados. De forma geral, a presença de MCNR nos cromatogramas é associada a resíduos de petróleo degradados ou resistentes (Readman et al., 2002). No ponto Rio Madeira VII (Porto Velho-RO) verifica-se que o valor de MCNR (Tabela 2) se apresentou bem mais alto que nos demais pontos. Aboul-Kassim \& Simoneit (2001)

Tabela 2 - Resultados do somatório de hidrocarbonetos alifáticos das amostras

\begin{tabular}{lrrr}
\hline & Rio Madeira VII & Rio Madeira IX & Rio Madeira X \\
\hline Hidrocarbonetos resolvidos & 750,35 & 0,07 & 0,52 \\
MCNR & 1571,15 & 1,861 & 1,861 \\
Total de alifáticos & 2321,49 & 0,07 & 0,52 \\
Recuperação (\%) & 52,6 & 46,14 & 95,76 \\
\hline
\end{tabular}

Os isoprenóides pristano e o fitano não são componentes primários da biota terrestre, sendo constituídos pela alteração geológica do fitol, onde, caso o pristano apresente maior abundância em relação ao fitano, a fonte de hidrocarbonetos predominante é de origem petrogênica (Wang et al.,1999, Wu et al., 2001). Apenas o ponto Rio Madeira VII apresentou a razão pristano/fitano (Tabela 3 ) ligeiramente $>1$ e o hidrocarboneto mais abundante foi $\mathrm{C}_{17}$ indicando que o aporte de hidrocarbonetos é predominantemente de fonte biogênica. Em complemento a essa afirmação, para o mesmo ponto verifica-se que a razão $\leq \mathrm{C}_{20} / \mathrm{C}_{21} \geq$ apresentou valor $>1$ e, segundo Commendatore \& Esteves (2004), esta ocorrência indica a entrada de hidrocarbonetos oriundos de plantas e algas. Segundo o mesmo autor, os hidrocarbonetos provenientes da degradação bacteriana, de plantas vasculares e da remobilização sedimentar resultam em baixos valores da razão $\leq \mathrm{C}_{20} / \mathrm{C}_{21} \geq$, resultado este observado nos pontos Rio Madeira IX $(0,5526)$ e Rio Madeira X $(0,2756)$, indicando que estes ambientes se mantêm relativamente conservados em relação a estes parâmetros.

A relação a $n-C_{17} /$ Pristano e $n-C_{18} /$ Fitano para o ponto Rio Madeira VII apresentou valor $>1$ indicando a ocorrência de emissão recente de óleo nessa localidade, sendo esta informação complementada pelo valor de MCNR mostrado na Tabela 3. Entretanto, a razão Resolvidos/MCNR indica que esse óleo recentemente introduzido se encontra em processo de degradação. 
Tabela 3 - Índices de diagnóstico dos n-alcanos analisados

\begin{tabular}{lccc}
\hline & Rio Madeira VII & Rio Madeira IX & Rio Madeira X \\
\hline Máximo & $\mathrm{C}_{17}$ & $\mathrm{C}_{12}$ & $\mathrm{C}_{27}$ \\
Resolvidos/MCNR & 0,4776 & 0,0376 & 0,2794 \\
$\leq \mathrm{C}_{20} / \mathrm{C}_{21} \geq$ & 3,4691 & 0,5526 & 0,2756 \\
Pristano/Fitano & 1,2140 & 1 & 1 \\
n- $\mathrm{C}_{17} /$ pristano & 2,0090 & 1 & 1 \\
$\mathrm{n}-\mathrm{C}_{18} /$ fitano & 2,2299 & 1 & 1 \\
\hline
\end{tabular}

Segundo ANA (2013), a porcentagem da população do estado de Rondônia não atendida por rede de esgoto é de $98 \%$, sendo que o município de Porto Velho - RO é um dos principais responsáveis pelos maiores valores de carga orgânica doméstica remanescente (14,8 t DBO/dia) entre os afluentes da margem direita da Bacia Amazônica (ANA, 2011). Contudo, através da análise do valor de MCNR e das razões $\mathrm{nC}_{17} /$ pristano e $\mathrm{nC}_{18} /$ fitano, verificou-se que ambiente sofreu contaminação recente de origem petrogênica. Estudos como o de Elcimar e Mariangela (2007) verificaram a contaminação dos aquíferos de Porto Velho ocasionada por vazamentos de tanques de armazenamento em postos de abastecimento, comprometendo a qualidade das águas dessa região, o que seria uma hipótese para o aporte dessas espécies de hidrocarbonetos nas águas às margens deste município.

\section{CONSIDERAÇÕES FINAIS}

O uso de índices de diagnóstico na aferição das fontes de aporte de hidrocarbonetos em águas superficiais mostrou-se uma técnica eficaz na averiguação do impacto ambiental de recursos hídricos. Dentre os pontos amostrados ao longo do trecho do rio Madeira apenas o ponto em frente ao Município de Porto Velho-RO apresentou ocorrência de contaminação recente de fonte petrogênica. No entanto este ponto também apresentou predominância de hidrocarbonetos de origem biogênica. Tendo por finalidade a tomada de iniciativas para o uso de tecnologias limpas para a remoção destes contaminantes que prejudicam a saúde e a qualidade de vida da população local.

\section{REFERÊNCIAS BIBLIOGRÁFICAS}

ABOUL-KASSIM, T.S.T.; SIMONEIT, B.R.T. Organic pollutants in aqueous-solid phase environments: types, analyses and characterizations. The hand. of envir. chem., v. 5, $105 p, 2001$.

ANA - AGÊNCIA NACIONAL DE ÁGUAS; Plano estratégico de recursos hídricos dos afluentes da margem direita do rio Amazonas. Vol. 1, Brasília: ANA, 2011.

ANA - AGÊNCIA NACIONAL DE ÁGUAS; Conjuntura dos recursos hídricos no Brasil. Brasília: ANA, 432p., 2013.

CARREIRA, R. S.; RIBEIRO, P. V.; SILVA, C. E. M.; FARIAS, C. O. Hidrocarbonetos e esteróis como indicadores de fontes e destino de matéria orgânica em sedimentos da Baía de Sepetiba, Rio de Janeiro. Química Nova, 2009, v. 7, p. 1805 - 1811, 2009. 


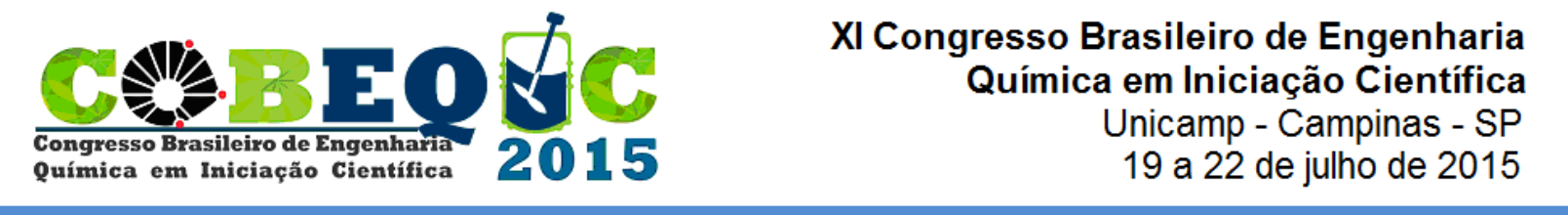

COMMENDATORE, M.G.; ESTEVES, J.L. Natural and anthropogenic hydrocarbons in sediments from the Chubut River (Patagonia, Argentina). Marine Pol. Bul. V. 48, p.910-918, 2004.

DICKENSON, E. R. V.; A SNYDER, S.; SEDLAK, D. L.; DREWES, J. E.; Indicator compounds for assessment of wastewater effluent contributions to flow and water quality., Water Res., V. 45, p. 1199-212, 2011.

EGLINTON, G.; HAMILTON, R. J.; .Leaf epicuticular waxes. Science, V. 156, p. 1322-1334, 1967.

FORTE, E. J.; AZEVEDO, M. S.; DE OLIVEIRA, R. C.; DE ALMEIDA, R.; Contaminação de aqüífero por hidrocarbonetos: Estudo de caso na vila tupi, Porto Velho - Rondônia, Quim. Nova, V. 30, p. 1539-1544, 2007.

GOULART, M. D. C.; CASTILHO, M.; Bioindicadores de qualidade de água como ferramenta em estudos de impacto ambiental. Rev. da FAPAM, V. 9, 2003.

LOUGON, M. S.; LOUZADA, F. L. R. O; ROCHA, S. A.; GARCIA, G. O.; SANTOS, A. R.; Diagnóstico ambiental da sub-bacia hidrográfica do córrego amarelo, abordando o uso e ocupação do solo e a qualidade da água. Eng. Ambiental, V. 6, p. 350-367, 2009.

READMAN, J.W.; FILLMANN, G.; TOLOSA, I.; BARTOCCI, J.; VILLENEUVE, J. P.; CATINNI, C.; MEE, L. D.; Petroleum and PAH contamination of the Black Sea. M. Pollution Bul., V. 44, p. 48-62, 2002.

WANG, Z.; FINGAS, M.; PAGE, D.S. Oil spill identification. Journal of Chromatography A, V. 843, p. 369-411, 1999.

WU, Y.; ZHANG, J.; MI, T.; LI, B. Occurrence of $n$-alkanes and polycyclic aromatic hydrocarbons in the core sediments of the Yellow Sea. Marine Chemistry, V. 76, p. 115, 2001. 